IP Periodica Polytechnica

Transportation Engineering

44(2), pp. 75-79, 2016

DOI: $10.3311 /$ PPtr. 8401

Creative Commons Attribution (i)

RESEARCH ARTICLE

\section{Assessment Approach of Life Cycle of Vehicles Tyres on Egyptian Road Network}

\author{
Ahmed Elkafoury ${ }^{1 *}$, Abdelazim Negm ${ }^{1}$
}

Received 10 July 2015; accepted 15 October 2015

\begin{abstract}
Recently the problem of used vehicle tires becomes in focus in Egypt. In this paper, the scope is to study life cycle of the yearly used tires by vehicles travelling on the Egyptian road network. For the first time, Life Cycle Assessment (LCA) approach is performed for tires used by the Egyptian road transportation fleet. Global Warming Potential (GWP), health toxicity, and Aquatic acidification are the main impact categories considered. The Life Cycle Impact Assessment Methodology (IMPACT2002+) is implemented for LCA analysis to encompass the transportation process of the yearly needed amount of tires, and the usage of the tires. At the nexus, data about transport demand and activity have been collected. Also, modal split ratios have been incorporated. It was found that, Egyptian road tires contributes mainly to GWP on the midpoint effect and also contributes mainly to the damage regarding terrestrial acidification and nitrification. Regarding the normalized effect, it was found that the highest contribution of used tyres on Egyptian road network is in respiratory effects on human health with $3.52 * 10^{4}$ (person year $/ \mathrm{kg}$ ) followed by terrestrial acidification of $3.1 * 10^{4}$ (person year $/ \mathrm{kg}$ ).
\end{abstract}

\section{Keywords}

Vehicle Tyres, Life Cycle Assessment, Egyptian road network, IMPACT2002+

\footnotetext{
${ }^{1}$ Environmental Engineering Department, Egypt-Japan University of Science and Technology (E-JUST),

P.O.Box 179, New Borg Al-Arab City, Postal Code 21934, Alexandria, Egyp

ResearcherID Ahmed Elkafoury: M-1221-2015

ResearcherID Abdelazim Negm: M-2808-2015

${ }^{*}$ Corresponding author, e-mail: ahmed.elkafoury@ejust.edu.eg
}

\section{Introduction}

In general Mass and people transportation operation is highly contributor to environmental problems involving noise, emissions, and also climate changes (Elkafoury et al., 2015). One highly emitting transportation related stage is the cars production. It leaves a giant footprint during its life time because materials like steel, rubber, glass, plastics, paints, and many more are related to the car production, usage, and waste. Among different vehicle production related industries, tires are one of the most harmful car related products (Torok, 2015). According to reports from The Japan Automobile Tire Manufacturers Association (JATMA), Rubber Manufacturers Association of USA (RMA), - World Business Council for Sustainable Development (WBCSD), the annual global production of tires is some 1.4 billion units. About 800 million scrap tyres every year producing 17 million tons of used tires each year (Sienkiewicz et al., 2012).

This amount, of course, is responsible for different negative effects on human health and environmental degradation during its life cycle. Abandoned or stockpiled scrap tires can be a source of breeding grounds for vectors such as rodents and mosquitoes. The curvy structures of scrap tires create stagnant water pools, making them an ideal place for breeding. Mosquitoes are known to carry fatal diseases such as Dengue Fever and Encephalitis (Fiksel et al., 2011). This is in addition to that during the period of tire use, $92 \%$ of the environmental impact of tires is created.

Life cycle assessment (LCA) is considered as an efficient and comprehensive tool to evaluate the environmental impacts of a product throughout its life cycle, starting with the extraction and processing of raw materials, manufacturing and production, product transportation, use and maintenance, until its waste disposal (Li et al., 2014). The survey of the literature indicates that no LCA-based-studies were published related to the vehicle tires Egypt and hence the environmental impacts of these tires are not investigated yet. Therefore, the objective of this paper is to perform - for the first time- impact assessment of the usage stage of the tire life cycle with application on tires used by Egyptian vehicle fleet. The paper consists of 
five main sections. In the second section, the types and sources of data used for performing the life cycle assessment are illustrated. The third section estimates the yearly amount of tires used on Egyptian road network, and split it among different vehicle categories. The fourth section includes calculations of amounts of pollutants related to importing needed amount of tires from south east of Asia. Finally, the fifth section implements The Life Cycle Impact Assessment Methodology based on IMPACT2002+ to calculate impact indicators of tires used on Egyptian road network considering different impact categories. IMPACT2002+ LCA methodology calculates impact for 100 years horizon.

\section{Data collection and methodology}

Data is the backbone of any life cycle assessment process. In this paper, data about number of licensed vehicles, distribution of vehicle fleet percentage, and emission rates are essential. In year 2012, numbers of licensed vehicle in Egypt and its share among different types of vehicles are collected from Central Agency for Public Mobilization and Statistics (CAPMAS, 2012) as shown in Table 1. It indicates that, in year 2012, number of licensed passenger cars in Egypt was 5,121,520 vehicles which share the highest percentage among the number of licensed vehicle in Egypt with about $81 \%$ of the total number. In the second rank, number of licensed trucks was 944,111 vehicle representing $15 \%$ of the total licensed vehicle number in Egypt. The lowest percentage share belongs to motorcycles with only $1 \%$ of the total licensed vehicles in Egypt.

Table 1 Number of licensed vehicles and percentage share among different vehicle categories in Egypt for year 2012

\begin{tabular}{lcc}
\hline Vehicle category & No. of licensed vehicles & \% Share \\
\hline Passenger cars & 5121520 & 81 \\
Bus & 183834 & 3 \\
Truck & 944111 & 15 \\
Motor cycle & 75012 & 1 \\
\hline
\end{tabular}

On the other hand, the yearly number of vehicle tires used on Egyptian road network is updated using Eq. (1).

$$
\mathrm{T}=\sum_{I}\left(\frac{V T K_{i}}{65000}\right) * n_{i} * N_{i}
$$

Where:

T: Total yearly number of tires used on roads,

i: refers to the vehicle category (passenger cars, truck,...., etc), $\mathrm{VKT}_{\mathrm{i}}$ : Yearly vehicle kilometre travelled of the vehicle category $i$, $\mathrm{n}_{\mathrm{i}}$ : Standard number of tires in the vehicle of category $i$, and $\mathrm{N}_{\mathrm{i}}$ : Number of licensed vehicles in the vehicle category $i$.
For calculating emissions emitted from ships during the transportation of tires from its source countries to Egypt, emission factors of different pollutants in (grams $/$ ton-km) is extracted from (OECD, 1997). Amounts of emissions related to tire transportation can be calculated using Eq. (2):

$$
\mathrm{P}_{X}=\mathrm{E}_{X} * \mathrm{~W}_{t} * \mathrm{~K}
$$

Here:

$\mathrm{P}_{\mathrm{x}}$ : pollutant $\mathrm{x}$ in gram,

$\mathrm{E}_{\mathrm{x}}$ : emission factor of vessel for pollutant $\mathrm{x}$,

$\mathrm{W}_{\mathrm{t}}$ : total weight of tires transported in tons, and

$\mathrm{K}$ : transportation distance.

Moreover, tire wear emission factors of $\mathrm{PM}_{10}$ and $\mathrm{PM}_{2.5}$ used in this paper per vehicle category are obtained from (Ten Broeke et al., 2008). Finally, the impacts of total emissions produced from tires used on Egyptian road network links has been assessed based on the database of the Life Cycle Impact Assessment Methodology IMPACT 2002+ (Humbert et al., 2012). This is done by multiplying amount of emissions $(\mathrm{kg})$ by the characterization factors of every impact category in IMPACT2002+ database.

\section{Estimating yearly number of road based used tires}

Total Vehicle Kilometre Travelled (VKT) is one of the important transport indicators. VKT provides a proxy measure of the overall pressure on the environment from all forms of road transport. It provides (in average) information about how long the vehicle had travelled one year backward. The VKT is the product of multiplying the number of vehicles on a given road or traffic network by the average length of their trips measured in kilometres. In year 2012, the total VKM in Egypt is $2.46654603^{*} 10^{11}$ (veh.km), with an average VKT of the vehicle in year 2012 of about 39,000 km/year (World Bank, 2010). The VKT for the year 2012 for each vehicle categories obtained by multiplying the number of vehicles in the vehicle category from Table 1 by the average vehicle kilometre travelled in the same year. i.e. 39,000 km/year. Table 2 presents the VKT for the year 2012.

Table 2 Vehicle Kilometre Travelled of different vehicle categories in Egypt for year 2012

\begin{tabular}{ll}
\hline Vehicle category & VKT (veh.km) \\
\hline Passenger cars & $1.99739 * 10^{11}$ \\
Bus & 7169526000 \\
Truck & 36820329000 \\
Motor cycle & 2925468000 \\
\hline
\end{tabular}


In this paper, the average travelled distance during age for the steel belted radial tires is assumed 65,000 km (Beukering and Janssen, 2001). Also, based on visual observation of road traffic fleet in different road network links, ni is assumed to be 4, 6, 8, and 2 for the vehicle categories of Passenger cars, Bus, Truck, and Motor cycle respectively. The application of Eq. (1) for road transport vehicle fleet in Egypt for year 2012 indicates that the estimated total number of tires used on the Egyptian road network is $17,575,198$ vehicle tires. The investigation of number of tires used on the Egyptian road network on the base of vehicle category indicate that Passenger cars is the main consumer among different vehicle categories by about 12291648 tires per year dominating about $70 \%$ of the whole vehicle tire usage in Egypt. The second largest consumer of vehicle tires in Egypt are Buses which contribute by about $26 \%$ of the tire consumption in Egypt in year 2012. Figure 1 presents the tires consumption absolute numbers and percentage for different vehicles categories in Egypt.

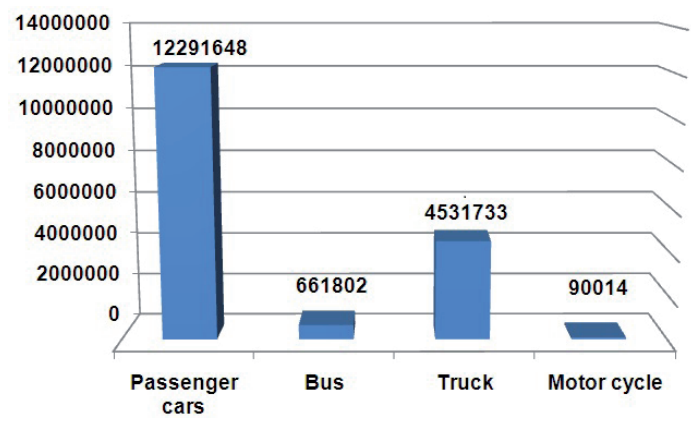

(a)

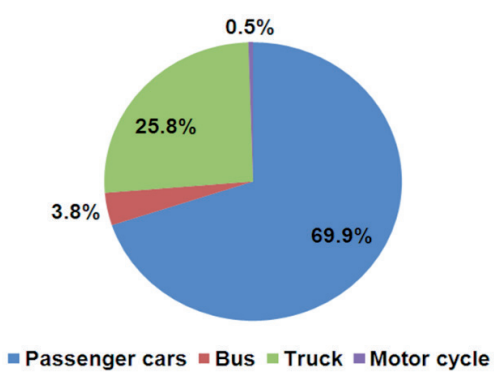

(b)

Fig. 1 Number of used tires by vehicle categories (a), and Distribution of tire usage among different vehicle categories (b) in Egypt in year 2012

\section{Emission calculations}

This section describes the methodology used for calculating amounts of emissions caused by the life cycle of the tyres used on Egyptian road network. It also includes estimating amounts of $\mathrm{CO}, \mathrm{CO}_{2}$, Hydrocarbons, $\mathrm{NO}_{\mathrm{x}}, \mathrm{SO}_{2}, \mathrm{PM}_{10}$, and VOC.

\subsection{Emissions Due to tires transportation}

The estimated yearly number of used tires is used for estimating the amount of emission related to it. As a matter of fact, no tire factories is established in Egypt and therefore, the estimated amount of tires is imported from abroad and mostly from South-East of Asia (e.g. from South Korea, Thailand, and China). It is transported to Egyptian market by the mean of maritime transport

Emissions Table 3 presents results of calculations for the amounts of different pollutants which is calculated using Eq. (2). In which, it is assumed that the average tire weight is $11 \mathrm{~kg}$ for passenger cars and motorcycles, $54 \mathrm{~kg}$ for trucks and buses. The total estimated weight of imported tyres, $\mathrm{W}_{t}$, is 416649187 tons which is obtained by multiplying the average weigh of tire by number of tires for each vehicle categories. On the other hand, the average transportation distance from SouthEast of Asia to Egypt across the oceans is about $8560 \mathrm{~km}$ as measured on google earth. network by applying the emission factors mentioned in the methodology.

Table 3 Amounts of most common emissions produced by ship transportation of tires needed for Egyptian road vehicle fleet in year 2012

\begin{tabular}{ll}
\hline Pollutant & Amount (kg) \\
\hline $\mathrm{CO}$ & 403016.4 \\
$\mathrm{CO}_{2}$ & $1.25 * 10^{8}$ \\
Hydrocarbons & 213991 \\
$\mathrm{NO}_{\mathrm{x}}$ & 1747593 \\
$\mathrm{SO}_{2}$ & 178325.9 \\
$\mathrm{PM}_{10}$ & 124828.1 \\
$\mathrm{VOC}$ & 356651.7 \\
\hline
\end{tabular}

\subsection{Emissions due to tires usage}

Traffic activities are considered major source of Particulate Matters (PM) in urban areas. Sources of PM from traffic are from tire wearing and fuel consumption. Figure 2 shows the amounts of $\mathrm{PM}_{10}$ and $\mathrm{PM}_{2.5}$ released from tire wearing of different vehicle categories in year 2012 on Egyptian road network by applying the emission factors mentioned in the Eq. (2).

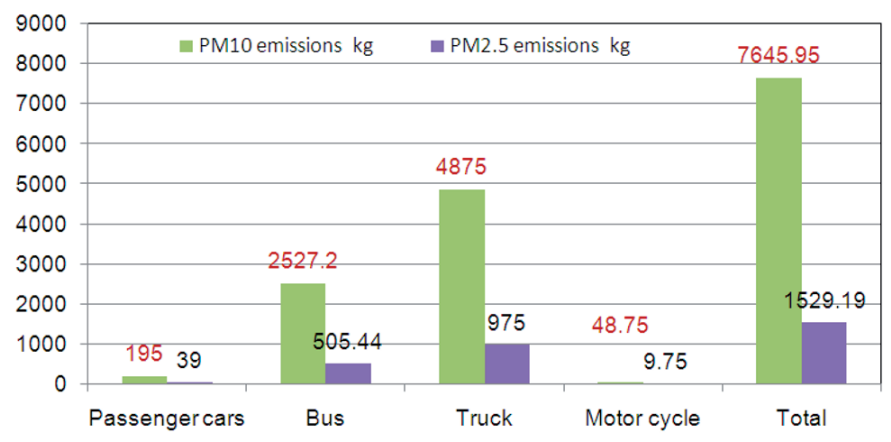

Fig. 2 Comparison between amounts of $\mathrm{PM}_{10}$ and $\mathrm{PM}_{2.5}$ from tire wearing of different vehicle categories in Egypt in year 2012 


\section{Environmental Impact assessment}

The impact of emissions from tires used on Egyptian road network links in year 2012 can be obtained by multiplying amount of emissions $(\mathrm{kg})$ by the characterization factors of every impact category in IMPACT2002+ database. On the midpoint characterization, results indicate that tires used on Egyptian road network in year 2012 contributes mainly in Global Warming Potential (GWP) with an impact of $1.26^{*} 10^{8}$ followed by a contribution in terrestrial acidification and nitrification of about $9.77 * 10^{6}$. It also contributes to respiratory effects on human health based on the midpoint characterization with $3.09 * 10^{5}$.

Regarding damage effect, tires used in Egypt contributes highly in terrestrial acidification and nitrification with about $1.02 * 10^{8}$. Respiratory comes on the second rank to have effects on human health with a damage of $2.16^{*} 10^{2}$. It also participates in photochemical oxidation and aquatic acidification with damage of 32.50 and 0.89 respectively. The participation of Egyptian road tires in GW damage is almost negligible. With respect to normalized effect, on the midpoint characterization, the highest contribution is in respiratory effects on human health with $3.52 * 10^{4}$ (pers.y/ $\mathrm{kg}$ ) followed by terrestrial acidification of $3.1 * 10^{4}$ (pers.y/kg). The analysis of normalized effect of damage indicates that the highest contribution to damage caused by tires on Egyptian road network is in respiratory effects on human health with $3.05 * 10^{4}$ (pers.y $/ \mathrm{kg}$ ) followed by terrestrial acidification of $7.37 * 10^{2}$ (pers.y $/ \mathrm{kg}$ ). These results are illustrated in Fig. 3.

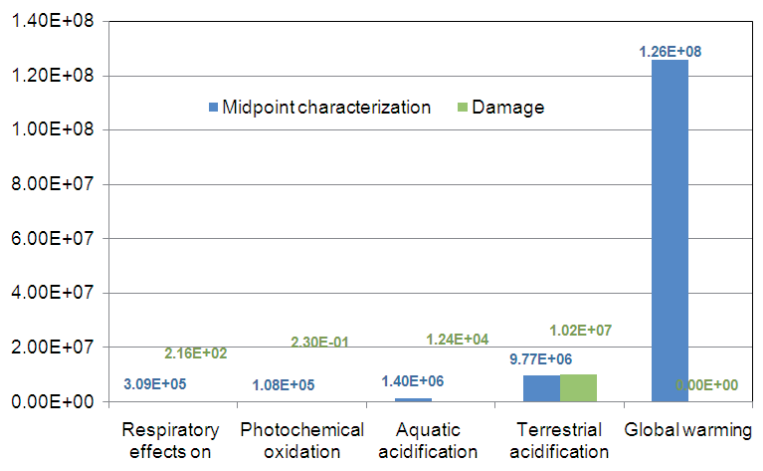

(a)

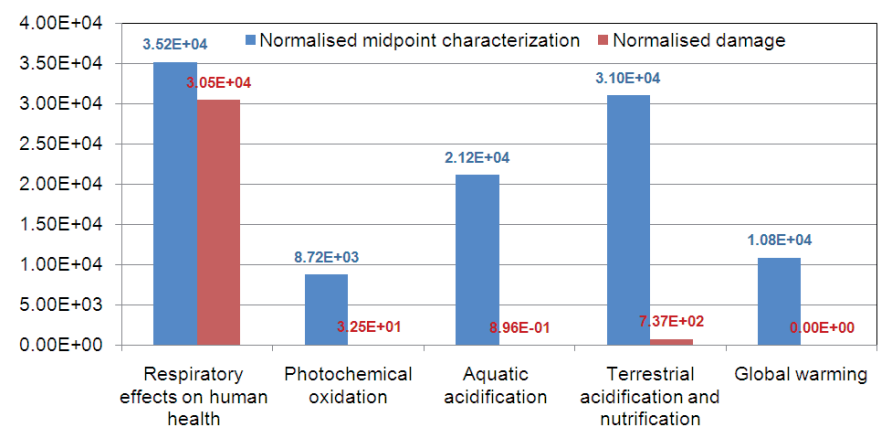

(b)

Fig. 3 Comparison between (a) Midpoint characterization and Damage Impact and (b) Normalized midpoint characterization and Normalized Damage Impact, for tires used on Egyptian road network in year 2012.

\section{Conclusions}

This paper scoped on study the life cycle of the tyres used yearly by vehicle fleet travelling on the Egyptian road network. The Life Cycle Assessment (LCA) approach has been conducted. This includes calculating amounts of tires involved yearly for the Egyptian vehicle fleet, and the distribution among vehicles types. Data about transport demand and travel activity has been collected and analysed. Also, modal split ratios have been incorporated. As all the vehicle tyres in the Egyptian market are imported from Asia, transporting of needed amounts of tires has also been studied to calculate amounts of emissions produced during import process. The Life Cycle Impact Assessment Methodology IMPACT2002+ approach has been utilized to detect the impact of pollutants related to Egyptian road tires on the environment. Results indicated that, Egyptian road tires contributes highly and mainly to GW on the midpoint effect and contributes mainly to the damage regarding terrestrial acidification and nitrification with about $1.02 * 10^{8}$. Regarding the normalized effect, it was found that the highest contribution is in respiratory effects on human health with $3.52 * 10^{4}$ (person year $/ \mathrm{kg}$ ) followed by terrestrial acidification of $3.1 * 10^{4}$ (person year $/ \mathrm{kg}$ ).

\section{Acknowledgement}

The first author would like to thank Mission DepartmentEgyptian Ministry of Higher Education (MoHE) and EgyptJapan University of Science and Technology (E-JUST) for their funding and scientific support.

\section{References}

Central Agency for Public Mobilization and Statistics (CAPMAS) (2012) Egyptian yearly statistical book.

Elkafoury, A., Negm, A. M., Aly, M. H., Bady, M. F., Ichimura, T. (2015) Develop dynamic model for predicting traffic $\mathrm{CO}$ emissions in urban areas. Environmental Science and Pollution Research. pp. 1-12. DOI: $10.1007 / \mathrm{s} 11356-015-4319-8$

Fiksel, J., Bakshi, B. R., Baral, A., Guerra, E., DeQuervain, B. (2011) Comparative life cycle assessment of beneficial applications for scrap tires. Clean technologies and environmental policy. 13(1), pp. 19-35. DOI: 10.1007/s10098-010-0289-1

Humbert, S., De Schryver, A., Margni, M., Jolliet, O. (2012) IMPACT 2002+: user guide. Draft for version Q, 2. [Online] Available from: http:// www.quantisintl.com/pdf/IMPACT2002_UserGuide_for_vQ2.21.pdf [Accessed: 12th August 2013]

Li, W., Wang, Q., Jin, J., Li, S. (2014) A life cycle assessment case study of ground rubber production from scrap tires. The International Journal of Life Cycle Assessment. 19(11), pp. 1833-1842.

DOI: $10.1007 / \mathrm{s} 11367-014-0793-3$

Organization for Economic Co-Operation and Development (OECD) (1997) The Environmental Effects of Freight.

Sienkiewicz, M., Kucinska-Lipka, J., Janik, H., Balas, A. (2012) Progress in used tyres management in the European Union: a review. Waste Management. 32(10), pp. 1742-1751. DOI: 10.1016/j.wasman.2012.05.010

Ten Broeke, H., Hulskotte, J., Denier van der Gon, H. (2008) Emission estimates for diffuse sources - Netherlands Emission Inventory: Road traffic tyre wear. Netherlands national water board - water unit. 
Torok, A. (2015) Importance of Tires: Case Study in Hungary. American Journal of Vehicle Design. 3 (1), pp. 27-30. DOI: 10.12691/ajvd-3-1-4

Van Beukering, P. J., Janssen, M. A. (2001) Trade and recycling of used tyres in Western and Eastern Europe. Resources, conservation and recycling. 33(4), pp. 235-265.

World Bank (2010) Egypt - Vehicle Scrapping and Recycling Program. Washington, DC: World Bank. [Online] Available from: http://documents. worldbank.org/curated/en/2010/04/12272064/egypt-vehicle-scrappingrecycling-program [Accessed: August 2010] 